\title{
Assessing fungal root colonization for plant improvement
}

\author{
Jose G. Maciá-Vicente, ${ }^{*}$ Hans-Börje Jansson and Luis V. Lopez-Llorca

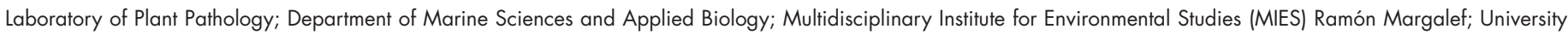 \\ of Alicante; Alicante, Spain
}

Key words: endophytes, Fusarium equiseti, fungal detection, mutualism, Pochonia chlamydosporia, root colonization

Fungal endophytes display a broad range of symbiotic interactions with their host plants. Current studies on their biology, diversity and benefits are unravelling their high relevance on plant adaptation to environmental stresses. Implementation of such properties may open new perspectives in agriculture and forestry. We aim to exploit the endophytic capacities of the fungal species Fusarium equiseti, a naturally occurring root endophyte which has shown antagonism to plant pathogens, and Pochonia chlamydosporia, a nematophagous fungus with putative endophytic behavior, for plant protection and adaptation to biotic and abiotic stress. A real-time PCR protocol for quantification of the fungal population, together with Agrobacterium-mediated genetic transformation with the GFP gene for confocal microscopy analyses, were designed and applied to assess endophytic development of both these fungal species. Although quantification of both $F$. equiseti and $P$. chlamydosporia yielded similar degrees of root colonization, microscopical observations demonstrated differences in infection and development patterns. Furthermore, we found evidences of plant response against endophyte colonization, supporting a balanced antagonism between the endophyte virulence and the plant defenses. Optimization and application of the methodologies presented herein will allow elucidation of beneficial interactions among these endophytes and their host plants.

Tissues of nearly all plants in natural ecosystems appear to be colonized by endophytic fungi, whose importance in plant development and distribution seem to be crucial, but not yet clearly

*Correspondence to: Jose G. Maciá-Vicente; Laboratory of Plant Pathology; Department of Marine Sciences and Applied Biology; Multidisciplinary Institute for Environmental Studies (MIES) Ramón Margalef; University of Alicante; Apto 99; Alicante 03080 Spain; Tel.: +34.96.5903400 ext. 3280; Fax: +34.96.5909897; Email: igmv@ua.es

Submitted: 03/11/09; Accepted: 03/12/09

Previously published online as a Plant Signaling \& Behavior E-publication: http://www.landesbioscience.com/journals/psb/article/8393

Addendum to: Maciá-Vicente JG, Jansson HB, Talbot NJ, Lopez-Llorca LV. Realtime PCR quantification and live-cell imaging of endophytic colonization of barley (Hordeum vulgare) roots by Fusarium equiseti and Pochonia chlamydosporia. New Phytol 2009; 182:213-28; PMID: 19170898; DOI: 10.1111/j.14698137.2008.02743.x. understood. Fungal endophytes may assist their host plants for adaptation to habitat, protection against biotic or abiotic stresses, plant growth promotion or soil nutrients uptake. ${ }^{1-5}$ Recently, biology and function of fungal endophytes in nature has been extensively reviewed, ${ }^{6}$ and these have been grouped into four classes according to their differential interactions with host plants, which may range from mere neutralism to an active mutualism.

Exploitation of beneficial properties of endophytes is of great relevance at an applied level, either to increase production yields of agricultural crops, control of plant diseases or pests, adapt plants to unsuitable growth conditions, or in reforestation activities. In this sense, we aim to exploit the endophytic capacities of selected fungi from two independent approaches: through the use of natural endophytes, which have shown to confer benefits to their host plants, ${ }^{5}$ or via a putative endophytic colonization of plant tissues by fungi with desirable properties. The latter strategy has been already introduced for several biological control agents such as nematophagous fungi colonizing roots, ${ }^{7}$ or entomopathogenic fungi in above-ground organs. ${ }^{8,9}$ As representatives of each category, we selected two fungal species according to their endophytic capacities and antagonism to root pathogens. ${ }^{10,11}$ First, Fusarium equiseti represents naturally occurring endophytes from natural vegetation growing under saline stress conditions. ${ }^{12}$ The second, Pochonia chlamydosporia, is a nematode egg-parasite which behaves as a putative endophyte of roots. ${ }^{13}$ Both species have promising properties for application as biocontrol agents of either fungal and/or nematode plant parasites. The achievement of these objectives will depend on an exhaustive knowledge on the endophytic behavior and interactions with the host and other existing microbes, which starts with the assessment of the establishment of fungal populations within plant organs (e.g., roots). In many instances this is a complicated task. Fungal growth is characterized by an implicit irregular development due to the filamentous nature of mycelia, whose complexity increases in structured substrates, such as the interior of plant tissues.

These difficulties are enhanced due to uneven distribution of nuclei (from zero to several thousands per cell), physiological activity or vitality of hyphae, and influence of competition among species. ${ }^{14}$ As a consequence of this, methods applied traditionally to estimate fungal occurrence within plant tissues (e.g., direct visualization, plating on culture media or immunolocalization ${ }^{4,15,16}$ ) 


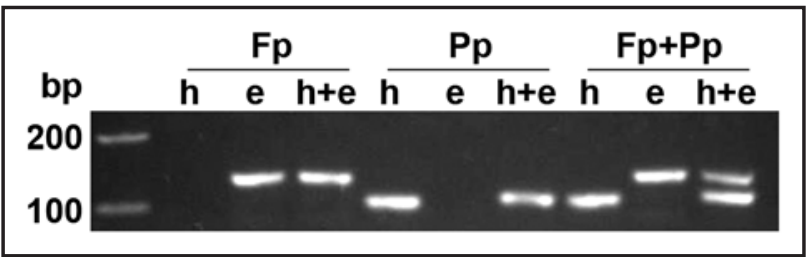

Figure 1. Amplification by conventional PCR of DNA from plant (h; barley), endophyte (e; P. chlamydosporia), or endophyte-colonized plants (h + e). For this, single locus detection with primers specific for the fungal alkaline serine protease $\mathrm{pl},{ }^{18}(\mathrm{Fp})$ and the plant ubiquitin $(\mathrm{Pp})$ is shown, and multiplex PCR using both primer pairs ( $\mathrm{Fp}+\mathrm{Pp}$ ) for one-tube simultaneous detection.

are biased or rather laborious and time consuming. Although applications of molecular methods have been directed to settle these problems, these may also present other weaknesses. Combination of quantitative and qualitative data achieved by both molecular and microscopy methods is probably the best choice to monitor fungi in plant roots, since the advantages of each technique may complement the drawbacks of the other. ${ }^{14,17}$

We recently optimized and applied both real-time PCR and microscopy techniques to exhaustively study the endophytic development of $F$ e equiseti and $P$. chlamydosporia in barley roots. ${ }^{18}$ The first approach consisted in a specific quantification of nucleic acids from either fungus in roots using Molecular beacon probes. ${ }^{19}$ This allows an accurate monitoring of the respective amplicon generation over PCR cyclings, which can be correlated with the amount of fungal biomass. ${ }^{20}$ Fungal populations detected in roots were statistically similar for both fungal species studied, with an overall colonization of roots which ranged from ca. 5 to $11 \mathrm{ng}$ of fungal target DNA per 100 ng of total DNA. The endophytic proportion of these populations (assessed by surface sterilization of roots prior to DNA extraction) was represented by values between ca. 0.5 to 1 ng of fungal target DNA per 100 ng of total DNA.

These quantitative data resulted in an increased sensitivity and dynamic range as compared with traditional culturing methods. Nevertheless, though quantification yielded good results under a gnotobiotic system, where only those fungi of interest are present within plant tissues, implementation for non-axenic semi-field or field experimentation should include modifications. These should cover corrections for presence of other colonizing microorganisms under non-axenic growth conditions-which may contribute to the amount of total DNA extracted from roots-, or variability on DNA extraction yields among samples. ${ }^{21}$ Inclusion of internal standards such as the simultaneous detection of fungal and host plant in a single reaction tube ${ }^{22}$ would settle these interferences. Multiplex PCR amplification of respective plant or fungal loci would permit detection of differential fluorescent signals emitted by Molecular beacons specific for either target DNA. We are currently optimizing primers and probes designed in Maciá-Vicente et al. ${ }^{18}$ for multiplexing with primers and Molecular beacons specific for the host (barley) ubiquitin gene (Fig. 1).

In addition to real-time PCR assays, endophytic behavior of $F$. equiseti and $P$. chlamydosporia was assessed using live-cell microscopy. Aiming to develop techniques for further studies in semi-field
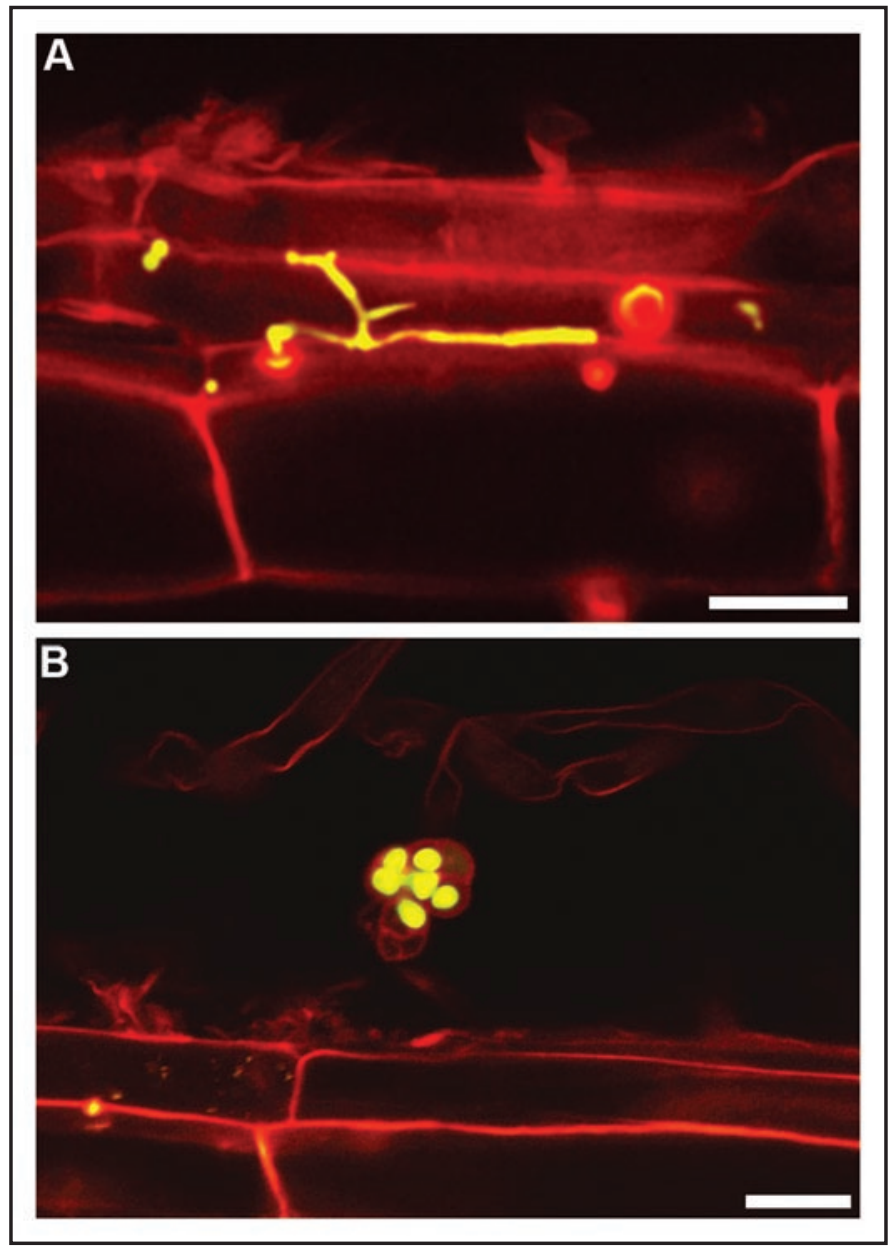

Figure 2. Laser scanning confocal microscopy images of one-monthold tomato roots colonized by GFP-tagged P. chlamydosporia. (A) P. chlamydosporia hypha restricted to a single epidermal root cell. (B) Chlamydospore in the root surface. Note GFP fluorescence within cells (viable) in contrast to lack of fluorescence in peduncle (non-viable). Bars $=20 \mu \mathrm{m}$.

experiments, we generated genetically transformed isolates for both $F$. equiseti and $P$. chlamydosporia, with constitutive expression of the fluorescent reporter protein GFP. For this purpose an Agrobacterium tumefaciens-mediated protocol was applied due to its efficiency in fungal transformation. ${ }^{23}$ Observation of barley roots inoculated with $G F P$-tagged isolates under laser scanning confocal microscopy permitted a time-course qualitative monitoring of the infection processes by F. equiseti and P. chlamydosporia, which displayed different endophytic patterns. Loading studies with the endocytotic tracker FM4-64 allowed a discrimination of new traits of fungal colonization of roots. Fungal hyphae appeared tightly fitted in a plant membrane-derived sheath during the first invasive stages, in a similar manner to that which occurs during pathogenesis, ${ }^{24}$ but also in mutualistic interactions, ${ }^{25}$ indicating it may be (at least originarly) an unspecific barrier to fungal invasion. However, this membrane was lost with time, as a consequence of hyphal aggressiveness over plant cell infection. 
Differential wavelength emission between GFP and FM4-64 also allowed detection of a heterogeneous distribution of viable and non-viable hyphae within the root cortex, the latter linked to plant defense responses such as abundant production of papillae or vacuoles. This colonization pattern suggests that endophytic interaction established by both fungi is a "push and pull" balance between hyphal growth and the capacity of the plant to get rid of the invader. Yet we do not know whether remaining undegraded nucleic acids contents of within-cortex dead hyphae may contribute to fungal target DNA detection by real-time PCR. Although this fact may represent a bias for endophytes quantification, combination with microscopical analyses complements the information achieved.

We are currently investigating practical and theoretical aspects of the root inoculation of fungi with endophytic capabilities and antagonistic potential to root pathogens (fungi and nematodes). This research also includes evaluating root colonization abilities for different host plants, both monocots and eudicots. As an example, root colonization efficiency by $P$. chlamydosporia dramatically changes between barley and tomato. In the latter, hyphae within roots are sparse and restricted to epidermal root cells, ${ }^{13}$ with no evident connection between infected cells (Fig. 2A). In spite of this restricted distribution, fungal chlamydospores (the propagules usually found in $P$. chlamydosporia-harboring soils) may be frequently found on the root surface. Their viability (according to GFP expression in the cytoplasm), irrespective of that of surrounding hyphae (Fig. 2B), could support that root colonization creates a stable source of inoculum to sustain the populations of the microorganism in the rhizospheric soil. Our final goal is to optimize biocontrol performance and crop growth promotion by endophytes under agricultural conditions.

\section{Acknowledgements}

The authors want to thank Nuria Escudero Benito for assistance in Laser scanning confocal microscopy. This work was supported by grants from CICYT of the Spanish Ministry of Science and Innovation (AGL2007-60264 and AGL200800716/AGR).

\section{References}

1. Sieber TN. Fungal root endophytes. In: Waisel Y, Eshel A, Kafkafi U, eds. Plant Roots: The Hidden Half. $1^{\text {st }}$ Edn. New York: Marcel Dekker 2002; 887-917.

2. Rodriguez RJ, Redman RS, Henson JM. The role of fungal symbioses in the adaptation of plants to high stress environments. Mitigation and adaptation strategies for global change 2004; 9:261-72.

3. Rodriguez RJ, Redman RS, Henson JM. Symbiotic lifestyle expression by fungal endophytes and the adaptation of plants to stress: Unravelling the complexities of intimacy. In: Dighton J, White JF, Oudemans P, eds. The Fungal Community: its Organization and Role in the Ecosystem. $3^{\text {rd }}$ Edn. Boca Raton, FL: CRC Press 2005; 683-95.

4. Schulz B, Boyle C. The endophytic continuum. Mycological Research 2005; 109:661-86.

5. Rodriguez R, Redman R. More than 400 million years of evolution and some plants still can't make it on their own: Plant stress tolerance via fungal symbiosis. J Exp Bot 2008; 59:1109-14.

6. Rodriguez RJ, White JF Jr, Arnold AE, Redman RS. Fungal endophytes: diversity and functional roles. New Phytol 2009; DOI: 10.1111/j.1469-8137.2009.02773.x.

7. Lopez-Llorca LV, Jansson HB, Maciá-Vicente JG, Salinas J. Nematophagous fungi as root endophytes. In: Schulz B, Boyle C, Sieber T, eds. Microbial Root Endophytes. Berlin, Germany: Springer-Verlag 2006; 191-206.

8. Gómez-Vidal S, Lopez-Llorca LV, Jansson HB, Salinas J. Endophytic colonization of date palm (Phoenix dactylifera L.) leaves by entomopathogenic fungi. Micron 2006; 37:624-32.
9. Vega FE. Insect pathology and fungal endophytes. J Invert Pathol 2008; 98:277-9.

10. Monfort E, Lopez-Llorca LV, Jansson HB, Salinas J, Park JO, Sivasithamparam K. Colonisation of seminal roots of wheat and barley by egg-parasitic nematophagous fungi and their effects on Gaeumannomyces graminis var. tritici and development of root-rot. Soil Biol Biochem 2005; 37:1229-35.

11. Maciá-Vicente JG, Jansson HB, Mendgen K, Lopez-Llorca LV. Colonization of barley roots by endophytic fungi and their reduction of take-all caused by Gaeumannomyces graminis var. tritici. Can J Microbiol 2008; 54:600-9.

12. Maciá-Vicente JG, Jansson HB, Abdullah SK, Descals E, Salinas J, Lopez-Llorca LV. Fungal root endophytes from natural vegetation in Mediterranean environments with special reference to Fusarium spp. FEMS Microbiol Ecol 2008; 64:90-105.

13. Bordallo JJ, Lopez-Llorca LV, Jansson HB, Salinas J, Persmark L, Asensio L. Colonization of plant roots by egg-parasitic and nematode-trapping fungi. New Phytol 2002; 154:491-9.

14. Gamper HA, Young JPW, Jones DL, Hodge A. Real-time PCR and microscopy: Are the two methods measuring the same unit of arbuscular mycorrhizal fungal abundance? Fungal Genet Biol 2008; 45:581-96.

15. Bermingham S, Dewey FM, Fisher PJ, Maltby L. Use of a monoclonal antibody-based immunoassay for the detection and quantification of Heliscus lugdunensis colonizing alder leaves and roots. Microbial Ecol 2001; 42:506-12.

16. Landeweert R, Veenman C, Kuyper TW, Fritze H, Wernars K, Smit E. Quantification of ectomycorrhizal mycelium in soil by real-time PCR compared to conventional quantification techniques. FEMS Microbiol Ecol 2003; 45:283-92.

17. Seddas PMA, Arnould C, Tollot M, Arias CM, Gianinazzi-Pearson V. Spatial monitoring of gene activity in extraradical and intraradical developmental stages of arbuscular mycorrhizal fungi by direct fluorescent in situ RT-PCR. Fungal Genet Biol 2008; 45:1155-65.

18. Maciá-Vicente JG, Jansson HB, Talbot NJ, Lopez-Llorca LV. Real-time PCR quantification and live-cell imaging of endophytic colonization of barley (Hordeum vulgare) roots by Fusarium equiseti and Pochonia chlamydosporia. New Phytol 2009; 182:213-28.

19. Tyagi S, Kramer FR. Molecular beacons: Probes that fluoresce upon hybridization. Nature Biotechnol 1996; 14:303-8

20. Schena L, Nigro F, Ippolito A, Gallitelli D. Real-time quantitative PCR: A new technology to detect and study phytopathogenic and antagonistic fungi. Eur J Plant Pathol 2004; 110:893-908.

21. Waalwijk C, Van Der Heide R, De Vries I, Van Der Lee T, Schoen C, Costrel-de Corainville $\mathrm{G}$, et al. Quantitative detection of Fusarium species in wheat using TaqMan. Eur J Plant Pathol 2004; 110:481-94.

22. Winton LM, Stone JK, Watrud LS, Hansen EM. Simultaneous one-tube quantification of host and pathogen DNA with real-time polymerase chain reaction. Phytopathology 2002; 92:112-6.

23. De Groot MJA, Bundock P, Hooykaas PJJ, Beijersbergen AGM, Chapman JW. Agrobacterium tumefaciens-mediated transformation of filamentous fungi. Nat Biotechnol $1998 ; 16: 839-42$.

24. Kankanala P, Czymmek K, Valent B. Roles for rice membrane dynamics and plasmodesmata during biotrophic invasion by the blast fungus. Plant Cell 2007; 19:706-24.

25. Genre A, Chabaud M, Timmers T, Bonfante P, Barker DG. Arbuscular mycorrhizal fungi elicit a novel intracellular apparatus in Medicago truncatula root epidermal cells before infection. Plant Cell 2005; 17:3489-99 